\title{
Exploring the Links between Employment Clusters and Economic Diversity in the British Urban System
}

\author{
Daniel 0'Donoghue \\ School of Human and Life Sciences, Canterbury Christ Church University, Canterbury, UK \\ Email: daniel.donoghue@canterbury.ac.uk
}

Received 5 April 2016; accepted 11 July 2016; published 14 July 2016

Copyright (C) 2016 by author and Scientific Research Publishing Inc. This work is licensed under the Creative Commons Attribution International License (CC BY). http://creativecommons.org/licenses/by/4.0/ c) (i) Open Access

\section{Abstract}

A growing body of literature, built up over the years, has explored the cluster concept. In parallel, another body of literature has accumulated regarding the diversity and specialisation of cities. There has been little explicit linkage between these two bodies of literature. This study sets out to explore the potential link between these two representations of spatial patterns so that a better understanding of the relationship between the two might be established. The UK Annual Business Inquiry 2007 provides the employment data drawn from various aggregated levels of the SIC 2003 for 70 TTWAs that represent the British Urban System. The paper investigates the extent of spatial concentration of individual sectors, and provides an example of how clusters might be identified spatially. Further analysis, using data drawn from the SIC 1, 2 and 3 digit levels indicates the relationship levels diversity/specialisation have with the clustering of activities, particularly when various sub-sectors are examined. Specific locations, or groups of cities are identified, which reinforce previous understandings of some of the key concepts. The results indicate further analysis of the role of localisation and urbanisation economies and their relationship with diversity/specialisation is required with an added emphasis on occupational, rather than just industrial diversity.

\section{Keywords}

Clusters, Concentration, Diversity, Specialisation, British Urban System

\section{Introduction}

Over the past 20 years an immense, if somewhat contentious, body of research has evolved exploring the cluster concept. Similarly, but over a somewhat longer period the concept of regional and urban economic diversity, or 
inversely specialisation, has also evolved. What is patently clear is that each body of research has been based on various conceptualisations, theoretical underpinnings and measurements. At various stages in the evolution of the concepts outlined above urban geographers, economic geographers, urban and regional scientists, economists and people from the world of business have all made their contribution. In each instance the approach involved has been well documented and understood, though mutual agreement has not always been reached as much of the research could only be found in subject specific arenas. More and more, and probably the direct outcome of the emergence of the New Economic Geography in the early 1990s, researchers in different academic realms have become more aware of what has been happening in each other's disciplines. What may have appeared to be disarray, now offers the potential for unity. While not naive enough to think some grand theory or unification is possible, all the approaches and debates surrounding clusters and specialisation do share one thing in common-the premise that there is something distinctive, if not unique, about either the places or industries examined - the key differences are those of purpose, emphasis, scale and location of analyses. Once these differences are recognised one can begin to draw together all strands of the existing research.

Considering the above, it is the intention of this paper to explore the context for a link between spatial concentrations of activity, clustering of economic activity and the levels of diversity/specialisation in the urban system of Great Britain. The analysis of the data should be considered secondary to the questions that are raised surrounding the links between clustering and diversity. The paper should be considered as a first step towards formally linking these two concepts together. It is envisaged that future research will delve even deeper into the relationship at both a conceptual and empirical level. The following section will review the previous research on clusters and diversity with an eye towards identifying the wide variety of issues that have emerged. This will be followed by a presentation of the data and methodologies used for this study. The analysis of the British Urban System comes next along with a section interpreting the results within the framework of existing conceptualisations. Finally, the paper concludes with the identification of future avenues for research that will draw upon the findings of this initial exploration.

\section{The Clustering of Economic Activity}

It is not the purpose of this paper to regurgitate all aspects of the cluster concept and its evolution. This has been done by many before, but what is important is to identify some of the problems surrounding the cluster concept, in particular as it may relate to the levels of diversity and specialisation in cities. Since the emergence of the concept there has been a tremendous amount of debate surrounding what actually constitutes a cluster. While the underlying theories and various conceptualisation of "clusters" have been with us for over 100 years it is really only since the 1990s that they have been popularised to the extent that they have "become a world-wide fad, a sort of academic and policy fashion item”, Martin and Sunley [1]. As Martin and Sunley point out much of this is the result of the popularisation of the works of Porter and Krugman. They identify why Porter's concept has become mainstream and highlight the fact "that economic geographers have taken a back seat in the discipline's research agenda". Their key criticism of the cluster concept as (re)conceived by Porter is "the definitional and conceptual elasticity of the cluster concept", and while they can see how this can be a strength they also identify how they consider it to be problematic.

The problem of definition, and in Porter's case definitions of the geographical scale at which clusters operate, lead to what Martin and Sunley [1] refer to as "this geographic license that has given authors unlimited scope in definition and application of the concept". The problems of cluster definition and a lack of spatial precision only lead to confusion and from a geographic perspective "do not aim to identify the location of agglomerations", Brenner [2]. While confusion exists surrounding the spatial extent of clusters there seems to be just as much confusion about their measurement, Vom Hoff and Chen [3], though some attempts have been made to make these measurements less arbitrary, O’Donoghue and Gleave [4]. Therefore, it is clear to see that much of the previous geographical research has focused on issues of definition, spatial extent and measurement.

Others question the utility of clusters as the focus of policy intervention when viewed as the answer to issues of regional competitiveness Kitson et al. [5] As so much of the cluster concept literature in recent years has come from the United States one must consider that, "it makes little sense to apply a conceptual and methodological framework - based as it is on the specificities of the American context-in other empirical settings without significant reflection, modification or adaptation”, Spencer et al. [6]. In addition, the same authors point out that the evidence remains remarkably scarce that clusters have any bearing on economic performance while others remark that their presence is overstated, Coe and Townshend [7]. As stated earlier this paper does not in- 
tend to answer all of these questions. However, the intention is to specifically link the cluster concept to an exploration of the levels of diversity and specialisation across an urban system.

\section{The Diversity and Specialisation of Economic Activity in Cities}

As with clusters that has been a wide range of research on the diversity and specialisation of economic activity in cities. This work can be traced back at least 50 years in the geographical literature. While perhaps not as confusing as the cluster concept, there has also been great debate within the diversity/specialisation literature on its conceptualisation, measurement and importance to policy prescription. This confusion perhaps derives from the intent of the various researchers, whether they have been urban or economic geographers, regional scientists, urban economists or people from the business world. Each group has its own purpose and interpretation when conducting research that reflects their chosen field of study. Bishop and Gripaois [8] have made an excellent contribution to the subject by reviewing the different actors and calling for all aspects of diversity research to be considered.

One could argue that the earliest work on the diversity of cities was concerned with understanding why cities had differing employment structures and how this related to city size, regional location, population growth or variables such as unemployment—in effect examining the determinants of diversity Bishop and Gripaois [8], O’Donoghue [9], Tarzwell [10], Davies and Donoghue [11]. This then evolved into a more widespread study of the links between diversity and performance, in particular the link between diversity and economic stability Dissart [12]. Others have linked changing levels of diversity, i.e. diversification, to global economic changes that have impacted on local economies or have examined whether diversification policies could succeed Shearmur and Polese [13]. There has been a wide range of studies from different countries at different scales of analysis. The study of diversity/specialisation, depending on where you come at it from, has strong grounding in industrial organisation theory, economic base theory, regional business cycle theory, trade theory, portfolio theories Seigel et al. [14] and various other location and regional economic theories, e.g. the product life cycle Duranton and Puga [15]. As with the study of clusters this has led to a variety of measures of diversity/specialisation which has formed the basis for numerous contributions from a wide range of authors each calling for the primacy of their approach.

In the same way as there was an explosion in interest in the clustering of activity in the 1990s there seems to have been an increase in interest in diversity related studies over the past 15 or so years. This was probably unavoidable, if not directly related, given the increased interest in clusters described above. The study of diversity seems to have matured over the past 10 years, but unlike the cluster concept its analysis is usually conducted in clearly defined spatial units, usually cities and regions. Unlike cluster research the diversity research would appear to be more systematic, in that a particular city or region is not just selected at random for analysis, but each city or region is analysed as part of a wider study usually into a national economy or urban system.

What is of particular interest to this paper is the way in which diversity researchers seem to have matured and begun to delve deeper into the concepts of diversity and specialisation, and via the latter opening the way to explore the links between clusters and specialisation. What is becoming apparent is that diversity is a "complex and heterogeneous phenomenon" and different types of diversities have been described, e.g. "related and unrelated diversity" Bishop and Gripaios [16] and what has also been termed "related and unrelated variety" Frenken et al. [17]. Similarly, while the vast majority of work on diversity was based on measures of industrial employment there seems to be a move towards including a wider range of data; more emphasis on services O’Donoghue and Townshend [18] or more emphasis on occupations Markusen et al. [19], Tarzwell [10] and examining the changing relationship between both industrial and occupational trends in different types of place through time. This is reiterated by Currid and Solarick [20] who suggest that "occupational not industrial classifications are most accurate in their measurement of the human capital clustering”. Duranton and Puga [21] use occupational data to identify a shift from specialisation by sector to specialisation by function. Linked to the diversity/specialisation debate has also been the emergence of a new body of literature on distinctive cities (Markusen and Schrock [22]), divergent cities (Markusen and Schrock [22]), (O’Donoghue and Townshend [18]) and creative cities (Scott [23], Florida [24]). What is also interesting is that at different scales there are paradoxically simultaneous processes of diversification and specialisation taking place Cutrini [25], O'Donoghue and Townshend [18] as well as both diversity and specialisation co-existing in the same city Shearmur and Polese [13]. The concept of "multiple specialisations" Malizia and Ke [26] has re-emerged in work during the past decade Dissart 
[12], Wagner [27] the former being the first to suggest that this may be the way to link the cluster concept to diversity research, there is also a potential link here to the work of Neffke et al. [28] on industry relatedness. Currid and Stolarick [20] make a similar intimation in their work identified above when they state, "A solely industrial based analysis neglects the role of human capital in understanding clustering”. These recent findings in diversity research demonstrate that "diversity is a complex and multifaceted phenomenon” (Bishop and Gripaois [8]) and that there is plenty of room to extend the research further by exploring the links between diversity and clusters.

\section{Data and Techniques}

The UK Annual Business Inquiry 2007 was the source for data used in this study-the Annual Business Enquiry having replaced the Annual Employment Survey as the main source of employment data in the UK. The data set covered Great Britain (England, Scotland and Wales) and included data for over 26 million employees. The data were categorised using the Standard Industrial Classification (SIC) 2003 and were disaggregated to SIC 2, 3 and 4 digit levels. The Travel-to-Work Area (TTWA) was chosen as the spatial unit of analysis due to its strong correspondence to meaningful functional economic units. Only TTWAs with employment greater than 100,000 were included in the analysis. Thus, there are 70 TTWAs in the study with an employed population of just over 21.6 million persons. These 70 TTWAs offer a good insight into what can be recognised as metropolitan Britain and are taken to represent the British Urban System. 2007 was selected as the date for this analysis as this data now provides a benchmark in future years against which employment post-crises can be compared.

The SIC 2003 is made up of a series of hierarchical levels. As this research is interested in urban functions agriculture, fishing and forestry have been excluded from the analysis. The employment data was divided into three different sets of data. The purpose of using data aggregated at different levels is to enable the research to build up a picture of diversity/specialisation from the bottom up; at a range of scales as it were. The 1-digit data set was composed of 13 sectors; the 2-digit data set was composed of 53 sectors while the 3-digit data set was composed of 207 sub-sectors. Each of these is associated with a numeric tag, which ranges from one digit to three digit codes depending on how far down one drills into the classification. While the classification is hierarchical not all sectors have the same level of detail or similar number of categories, there is a historic bias towards manufacturing in the classification, i.e., there are far more sectors at the 2 and 3 digit levels of manufacturing than their proportional representation in the workforce would require, approximately half of all sub-sectors at the 3-digit level are part of the broader manufacturing sector. The use of different digit levels in the SIC is important because data aggregated at similar levels will form the basis of further analysis.

The study of clusters and diversity is often heavily influenced by the choice of data and this research recognises that. While most studies tended to choose only one industry or sector, or only draw data from one level in the SIC, it is a key part of this study to highlight the inter-relationships between data as levels chosen within the SIC change. In other words, how do measures of diversity or spatial concentration change as one goes from the general to the detailed or from highly aggregated data to highly disaggregated data? It has long been a criticism of work in this field that the level of diversity identified is dependent on the number of sectors chosen (based on the SIC digit level). With this in mind this research will draw upon a range of data at different SIC level so that differences in diversity and specialisation levels may be compared across subsectors of the SIC. In addition, various sub groupings of Manufacturing, Hi-Tech activity, Advanced Producer Services (APS) and Finance, Insurance and Real Estate (FIRE) were created so that they may be examined in addition to the headline figures. These sub-groups, all composed of sub-sectors at the 3-digit level of aggregation should provide further insights into the locational properties and tendencies of various sectors. The manufacturing sub-group included 100 sub-sectors, APS 16 sub-sectors, FIRE 12 sub-sectors and Hi-Tech 10 sub-sectors (not mutually exclusive from the manufacturing sub-sectors). These sub-groups were created so that the contribution of various sectors which have been shown to have specific locational tendencies in the literature, thus likely to cluster, could be examined independently.

The measures used throughout the remainder of this study have been well rehearsed in the study of diversity and spatial concentration. Location quotients are used to identify places that have the highest concentration of activity in each sector of the economy, for the purposes of this study a crude proxy for clustering or agglomeration of activity. Dissimilarity Indices are used to identify sectors that have tendencies towards ubiquitousness or extreme spatial concentration. Gini Coefficients are used across the different digit levels of the SIC and across different sub sectors to identify overall levels of diversity/specialisation and activity specific sub-patterns of di- 
versity/specialisation. To assist with the interpretation of the results Gini Coefficients will be standardised and mapped.

\section{The Location of Economic Activity in the British Urban System}

One approach to understanding the spatial tendencies for different sectors is to determine the extent to which those sectors, or activities, are spatially concentrated Polese and Shearmur [29]. In other words, are some sectors more likely to be found in relatively few places or in most places? The former would represent spatial concentration within the system the latter a tendency towards ubiquity. Based on previous work by O’Donoghue and Townshend [18] and O’Donoghue [30] it is clear that services, and in particular consumer services, are more ubiquitous. While that result is totally in keeping with theoretical expectations it is important at any moment in time to get some feel for the current state of play regarding the levels of employment concentration and dispersal in the system. Figure 1 identifies the least and most spatially concentrated sectors in the UK. The Dissimilarity Index score represents the mathematical distance each sector is from a perfectly even distribution throughout the urban system. The nearer to one the more spatially ubiquitous that sector. Very high scores indicate spatial concentration to the point where almost all employment in the system in a sector is located in one place.

It is clear from Figure 1 that at the 2-digit level Retail activity is by far the most ubiquitous, followed by a

\begin{tabular}{|c|c|}
\hline 2-Digit SIC Code and Sector Name & Dissimilarity Index \\
\hline 52 : Retail trade & 1.11 \\
\hline 80 : Education & 1.55 \\
\hline 85 : Health and social work & 1.61 \\
\hline 55 : Hotels and restaurants & 1.61 \\
\hline 92 : Recreational, cultural and sporting activities & 1.93 \\
\hline 74 : Other business activities & 2.04 \\
\hline 93 : Other service activities & 2.19 \\
\hline 50 : Sale, maintenance and repair of motor vehicles and fuel & 2.21 \\
\hline 45 : Construction & 2.40 \\
\hline 70 : Real estate activities & 2.50 \\
\hline 32 : Manufacture of radio, television and communication equipment and apparatus & 14.83 \\
\hline 34 : Manufacture of motor vehicles, trailers and semi-trailers & 14.85 \\
\hline 27 : Manufacture basic metals & 20.17 \\
\hline 35 : Manufacture of transport equipment & 21.65 \\
\hline 30 : Manufacture of office machinery and computers & 22.89 \\
\hline 19 : Tanning and dressing of leather; manufacture of luggage, handbags, saddlery, hamess and footwear & 27.08 \\
\hline 23 : Manufacture of coke, refined petroleum products and nuclear fuel & 28.33 \\
\hline 16 : Manufacture of tobacco products & 32.94 \\
\hline 10 : Mining of coal and lignite; extraction of peat & 56.97 \\
\hline 11 : Extraction of crude petroleum and natural gas and related service activities & 70.22 \\
\hline 3-Digit SIC Code and Sector Name & Dissimilarity Index \\
\hline 524 : Other retail sale of new goods in specialised stores & 1.17 \\
\hline 521 : Retail sale in non-specialised stores & 1.60 \\
\hline 853 : Social work activities & 1.71 \\
\hline 553 : Restaurants & 1.73 \\
\hline 801 : Primary education & 1.74 \\
\hline 851 : Human health activities & 1.83 \\
\hline 554 : Bars & 2.06 \\
\hline 522 : Retail sale of food, beverages and tobacco in specialised stores & 2.17 \\
\hline 930 : Other service activities & 2.19 \\
\hline 523 : Retail sale of drugs, medical goods, cosmetic and toilet articles & 2.20 \\
\hline 263 : Manufacture of ceramic tiles and flags & 49.19 \\
\hline 351 : Building and repairing of ships and boats & 50.49 \\
\hline 111 : Extraction of crude petroleum and natural gas & 53.63 \\
\hline 262 : Manufacture of non-refractory ceramic goods other than for construction purposes; & 54.32 \\
\hline 101 : Mining and agglomeration of hard coal & 58.45 \\
\hline 314 : Manufacture of accumulators, primary cells and primary batteries & 63.00 \\
\hline 247 : Manufacture of man-made fibres & 68.67 \\
\hline 112 : Service activities incidental to oil and gas extraction excluding surveying & 83.74 \\
\hline 143 : Mining of chemicals and fertiliser minerals & 91.17 \\
\hline 144 : Production of salt & 107.03 \\
\hline
\end{tabular}

Figure 1. 10 lowest and highest dissimilarity indices for SIC 2 and 3 digit sectors. 
range of other consumer services. Given this level of dispersal throughout the system consumer services are unlikely to play a major role in the differentiation of places across the system. At the other end of the spectrum industries linked to primary resources are spatially the most concentrated, but more general manufacturing activity does seem to be quite biased, e.g. manufacture of office machinery and computers or transport equipment. What perhaps is more interesting when one examines Figure 1 is that when one examines the sectors at 3 digit levels, the scores for the 10 least concentrated sectors are quite similar to those for the 2 sector case, while for the most concentrated sectors the scores get considerably higher. This indicates that at the 3 digit level some sectors have extremely high levels of concentration, and not just in resource related sectors that have a tradition of spatial concentration.

This type of analysis of concentration and dispersal, while seemingly peripheral to the main thrust of the research, is important as a first step towards understanding the links between the location of activities, clustering and diversity. Perhaps more interesting than the data in the table itself is its use to gain a feel for where these activities are located within the urban system. Just because an industry, or sector, has a very high score on Figure 1 does not mean it is representative of clustering, however it does indicate that much of that industry is located in a limited number of places within the urban system. Therefore, it may represent a tendency towards clustering.

To see where some of these high scoring sectors are located Figure 2 identifies the location of the highest location quotient in each of 156 selected 3-digit sectors. If a place has a number of sectors that score very highly this may be indicative of clustering, or at least relatedness Neffke et al. [28]. It is recognised that this approach is rather crude, however it is indicative of places that are highly specialised within the system in terms of specific industries, even if they are not necessarily related.

If one looks at the overall distribution it is clear to see that there are a limited number of places that have multiple sectors represented. The majority of these places are in and around the West Midlands and Northwest regions, traditional manufacturing regions. Three places that stand out from the map are Aberdeen, Worcester and Derby. Most of the sectors in Aberdeen are related to the oil industry, while Worcester and Derby are mainly in manufacturing sectors, and can be linked to particular industries or employers, e.g. Rolls Royce in Derby. What is also apparent is that few places in the South and East of the country have places that have numerous sectors represented, and there are 10 TTWAs that do not have a highest location quotient for any sector.

Another interesting feature to observe is the absence of industries with very large location quotients in the larger conurbations. Despite the West Midlands and Northwest regions being identified previously the cities of Birmingham and Manchester do not possess any industry that has a highest location quotient. Similarly, cities such as Sheffield and Newcastle, are among other traditional manufacturing centres that do not have these high concentrations either. Most of the other largest cities have only one, or at most 2, of the 207 sectors represented as a high scoring location on the location quotient. What this seems to suggest is that due to their size, and thus the presence of urbanisation economies, it is difficult for the larger cities to appear specialised. In fact, they may actually have "multiple specialisations" but they tend to get lost in the wider economy. The lack of strong specialisation into one particular sector may have an influence on subsequent measures of diversity whereby there is an effect such that any "multiple specialisations" present get masked. This would also result from the summative nature of the Gini Coefficient. It is hoped to gain more knowledge regarding this effect by looking at various constructions of the Gini Coefficient based on measuring diversity/specialisation at the 1, 2, 3-digit level from the SIC. It is anticpated that differing patterns will emerge depending on the level of aggregation used, or internally within specific sub-groups identified earlier.

\section{Diversity and Specialisation in the British Urban System}

The following figures examine Gini Coefficients across the British urban system for a range of sub sectors of the economy. As mentioned earlier the data were divided into subsectors: Manufacturing, Hi-Tech activity, APS and FIRE. This was done so that a more detailed picture of diversity and specialisation could be created. The majority of studies of on diversity and specialisation in the past have been rather uni-dimensional or uni-scalar in that they have chosen a set number of categories across which to measure diversity and then stuck with it. This study hopes to pick out subtle trends along the diversity/specialisation continuum by identifying sub trends within specific sectors, sub trends within different levels of the SIC and locational tendencies that might be identifiable through comparison of some of these. In addition to this novel approach, the data on diversity/specialisation will also be presented in a different fashion from the norm. Where the Gini Coefficient ranges in value from 0 to 1 it 


\section{Presence of the highest Location Quotient in one of 156 selected Sectors at 3 digit SIC level}

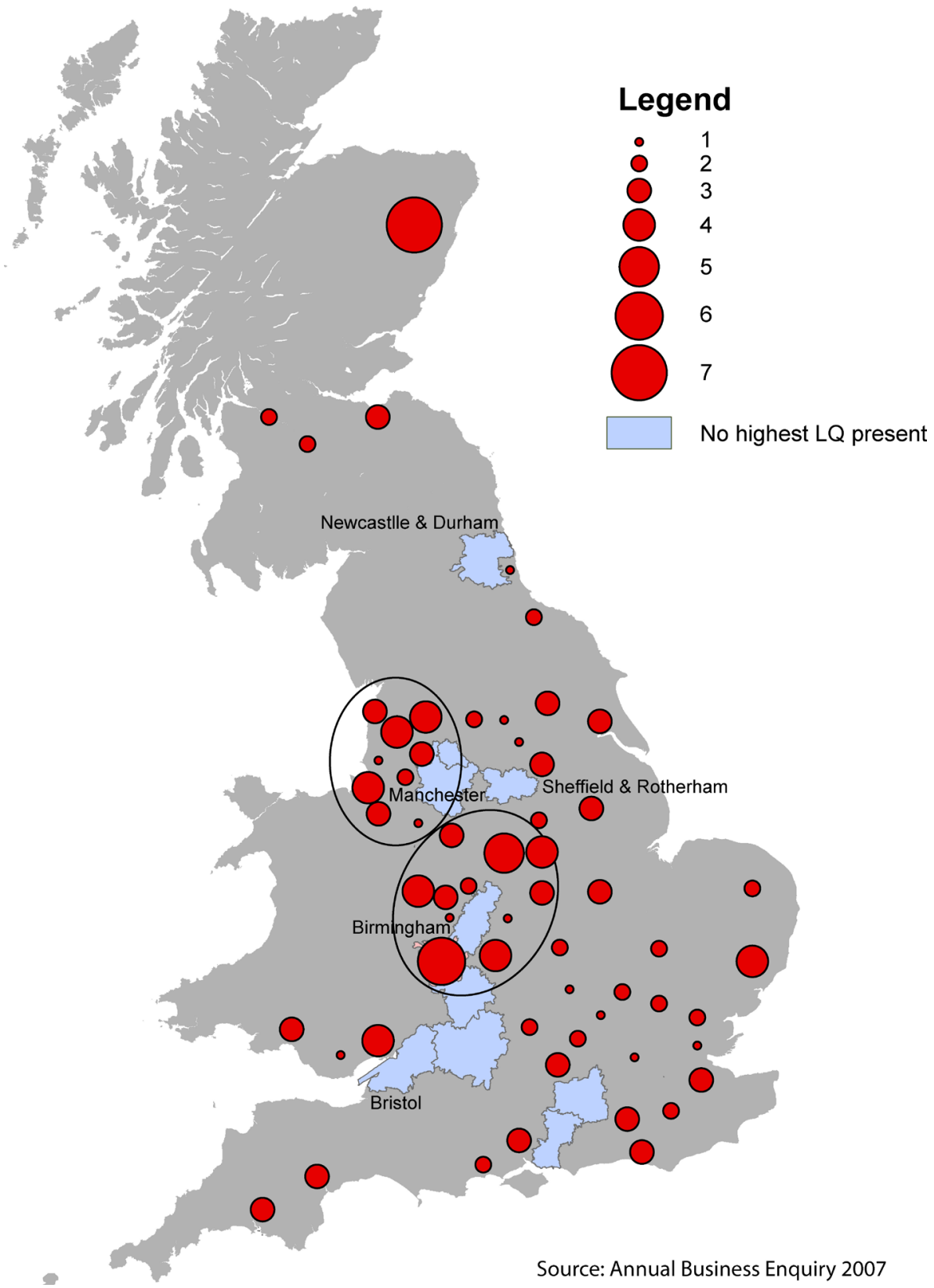

Figure 2. Number of sectors with highest LQ present.

can sometimes be quite difficult to pick out those subtle patterns and differences within the data, so it was felt that it would be more useful if the data could somehow be stretched so that interpretation of the results might be easier. In addition, standardisation of the Gini Coefficient allows for the bi-polar nature of the diversity/specialisation spectrum to be identified more clearly. Towards that end all measures of diversity/specialisation have been standardised, with strong negative scores reflecting high levels of diversity and strong positive scores reflecting high levels of specialisation. The following figures can now be explored. Figure 3 highlights patterns of 
diversity/specialisation within the manufacturing sector. Traditionally manufacturing has often been the reason why some places have been classified as specialised, but traditional measurement has not allowed us to glimpse within the sector. When we do so an interesting picture emerges. The most specialised locations tend to be in the north while the southeast of England is the most diverse, and has an apparent absence of specialisation. However, the pattern is not that simple.

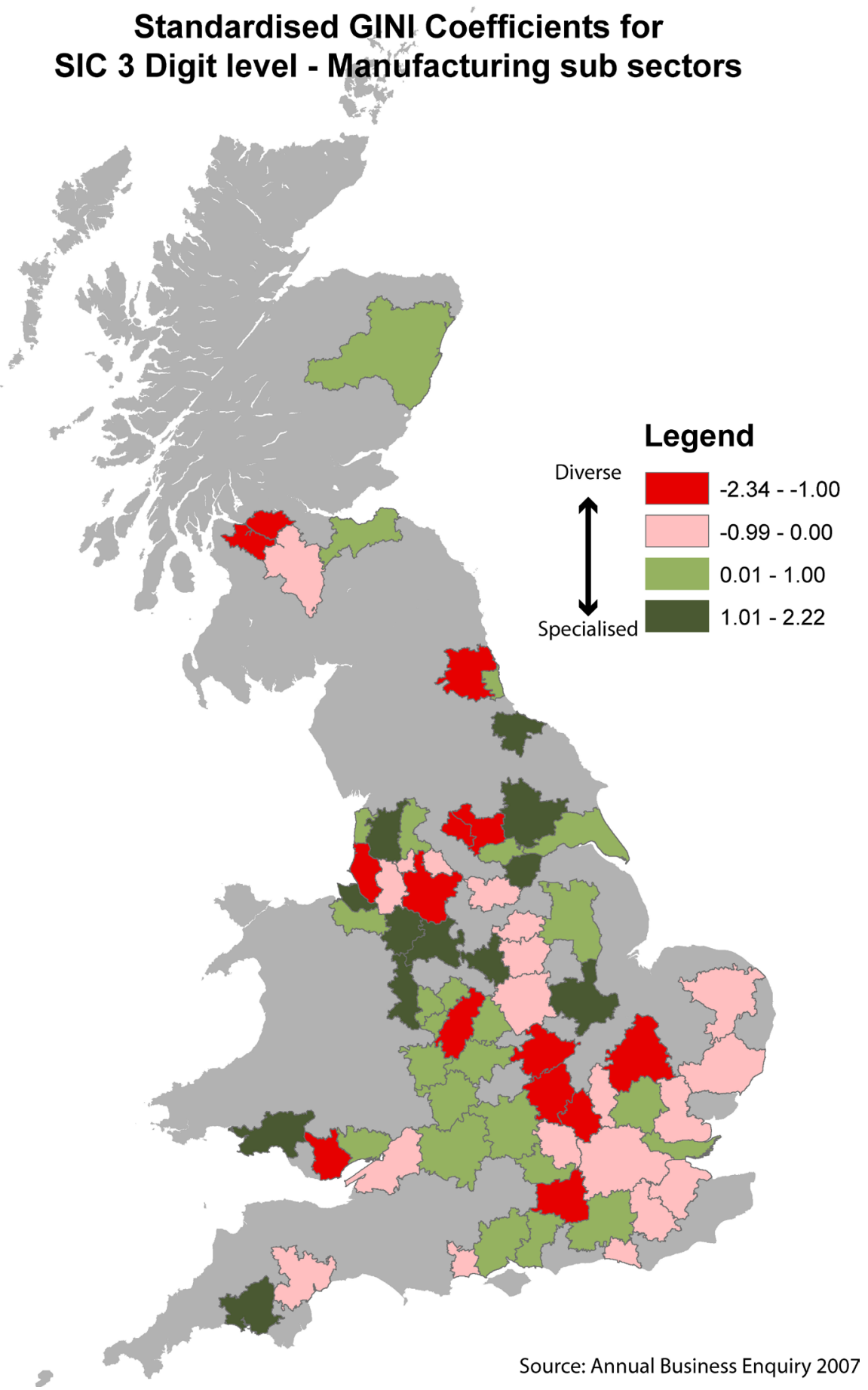

Figure 3. Gini Coefficients for manufacturing sub-sectors. 
While that may not be a new finding what does appear to be new is that traditional manufacturing regions of the UK have evolved or diverged into two tiers. This would seem to be confirmed when one considers the large metropolitan areas, or the first tier of the urban hierarchy. Birmingham, Manchester, Liverpool, Leeds, Newcastle and Glasgow, what most would describe as tradition British industrial cities, all among the top ten nationally in size terms, all emerge amongst the most diverse in terms of manufacturing. This implies, not that they don't have manufacturing, but that their manufacturing employment is very diverse, arguably a very clear indication of urbanisation economies at work. This is a huge change particularly for cities like Glasgow and Newcastle which traditionally would have been associated with specialisation in one industry: shipbuilding

The second tier seems to focus on limited numbers of industries, if not one particular industry, at particular locations. Cities in this tier include places such as Derby, Blackburn, Stoke, Middlesbrough and Doncaster. This seems to reflect flexible specialisation with different regions focusing on different sectors, in particular note the regional specialisation around Birmingham, and particularly to the north. It may also reflect that some of these second tier cities have retained some of their traditional industries and would seem to reflect some of the potential clustering identified in Figure 1 earlier, perhaps due to 'relatedness'. What it also would seem to suggest is the absence of urbanisation economies and a greater emphasis on localisation economies.

It would appear that manufacturing in the south east lacks sector specialisations found in the North and more traditional industrial regions of the country, and this is clearly the case when one looks at Figure 3 where no locations emerge as specialised. With that in mind, it was felt that perhaps the south east, with its well-documented dynamic economy, would be home to newer hi-tech activities not included in the manufacturing sector just discussed. To see if that is the case attention is now turned to the examination of diversity and specialisation within the hi-tech sectors.

If one examines Figure 4 what becomes clear is that a similar overall pattern appears to emerge as that seen in Figure 3 although there seems to be more dispersal of specialisation around some northern TTWAs. The southeast once again emerges as diverse and in particular very diverse to the west and south of London. These very diverse TTWAs are in a part of the south east region sometimes referred to as the 'western crescent' Duncan [31]. The lack of specialisation here when looking within hi-tech sectors suggests these places have a good distribution of high tech activity and would seem to be representative of urbanisation economies, drawing on the greater South east region. A number of larger cities also score as very diverse within this sector: Birmingham; Glasgow; and Newcastle.

Figure 5 presents a somewhat different but also very clear story about the internal levels of diversity and specialisation within the Advanced Producer Services sector. The specialised locations are rather smaller TTWAs distributed around the country and one place that clearly stands out when linked back to Figure 1 is Aberdeen. This appears as specialised because most of its APS are directly related to the oil-industry, a clear example of how the operation of a cluster may create localisation economies Chapman et al. [32]. In contrast, all the most diverse

TTWAs in this sub sector are either large cities—London, Birmingham, Leeds, Newcastle and Sheffield—or on London's periphery, in particular to the south and northeast. This shows the dominance of the southeast and larger cities and the role of urbanisation economies in this sub-sector. Large areas of the country are not well served by APS, but those that are have a wide range of these activities present. This is very much in keeping with the specialised locational expectations of this sector that has been well described in vast sections of the literature.

The final sub-sector to be examined is FIRE and these results are found on Figure 6. The results here are not dissimilar from those found for APS other than if anything there is a stronger bias of diversity of this subsector into the largest cities. London, Birmingham, Manchester, Glasgow, Liverpool, Sheffield, Bristol, Cardiff and Nottingham all emerge amongst the most diverse. These are not just large cities but cities with a better regional spread throughout the country than for any of the other sub-sectors, indicating not just diversity in these cities but that these cities are also fulfilling a role as regional financial centres offering the full range of financial services to their regions. This is exemplified by the presence of Glasgow and Cardiff as financial centres for Scotland and Wales, respectively but also Bristol and Nottingham serving the South West and East Midlands respectively. The most specialised places in the country are found in rather peripheral locations, Aberdeen once again appearing and reflecting the specialised financial activity linked to the oil industry there.

Now that we have seen some of the internal dynamics of diversity within various sub-sectors we can turn our attention back to the overall. The three maps in Figure 7 represent a drilling down through the SIC and measur- 
ing changes in diversity level as we do so. The SIC 1-digit section level represents diversity as measured with the fewest sectors, the SIC 3-digit level map on the right represents diversity as measured across a large disaggregated number of sectors.

There are some interesting results when one looks in detail across the 3 maps of Figure 7, but in particular three key elements which confirm some of the findings of the sub sector analysis. If one looks for stability of

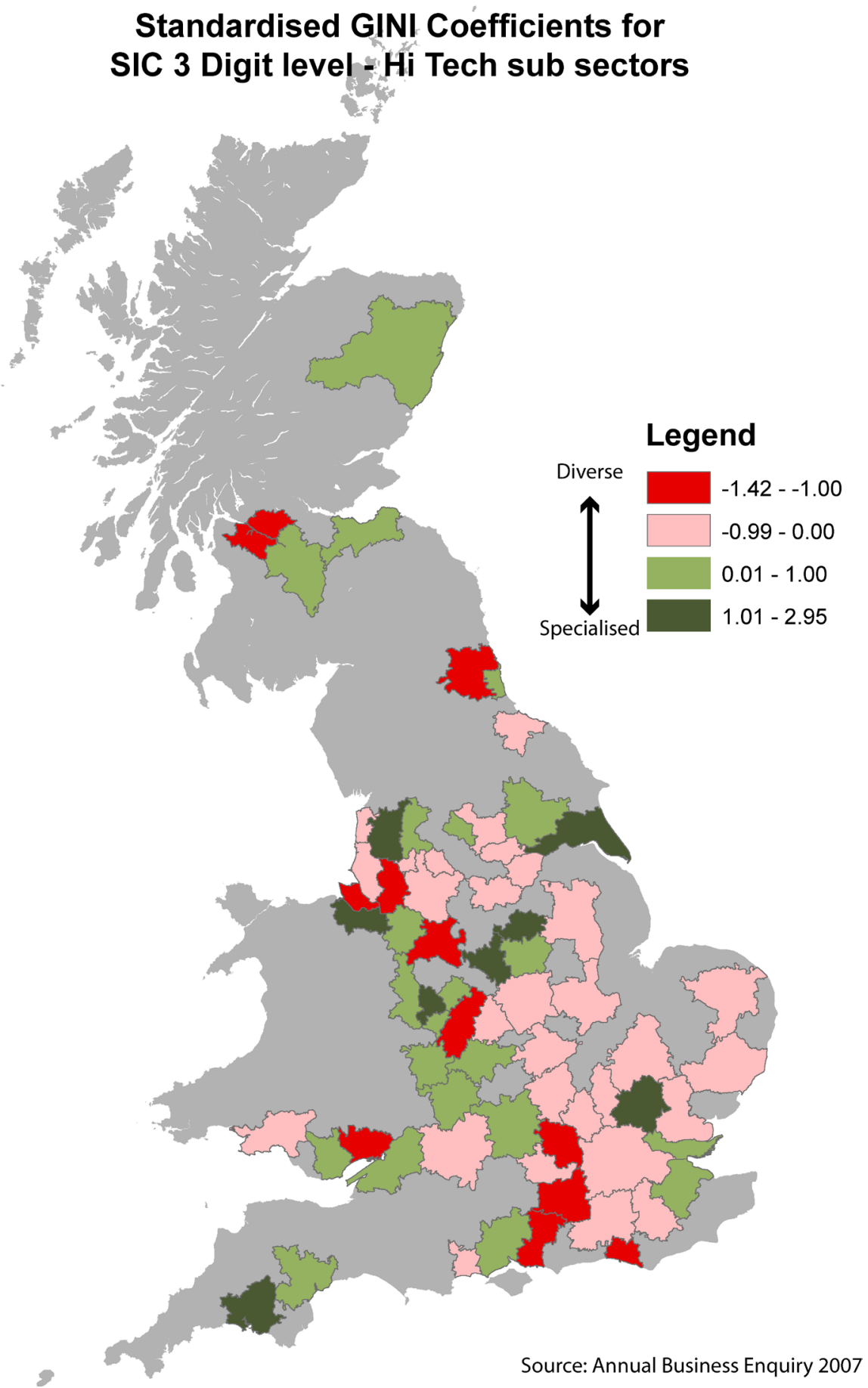

Figure 4. Gini Coefficients for hi-tech sub-sectors. 


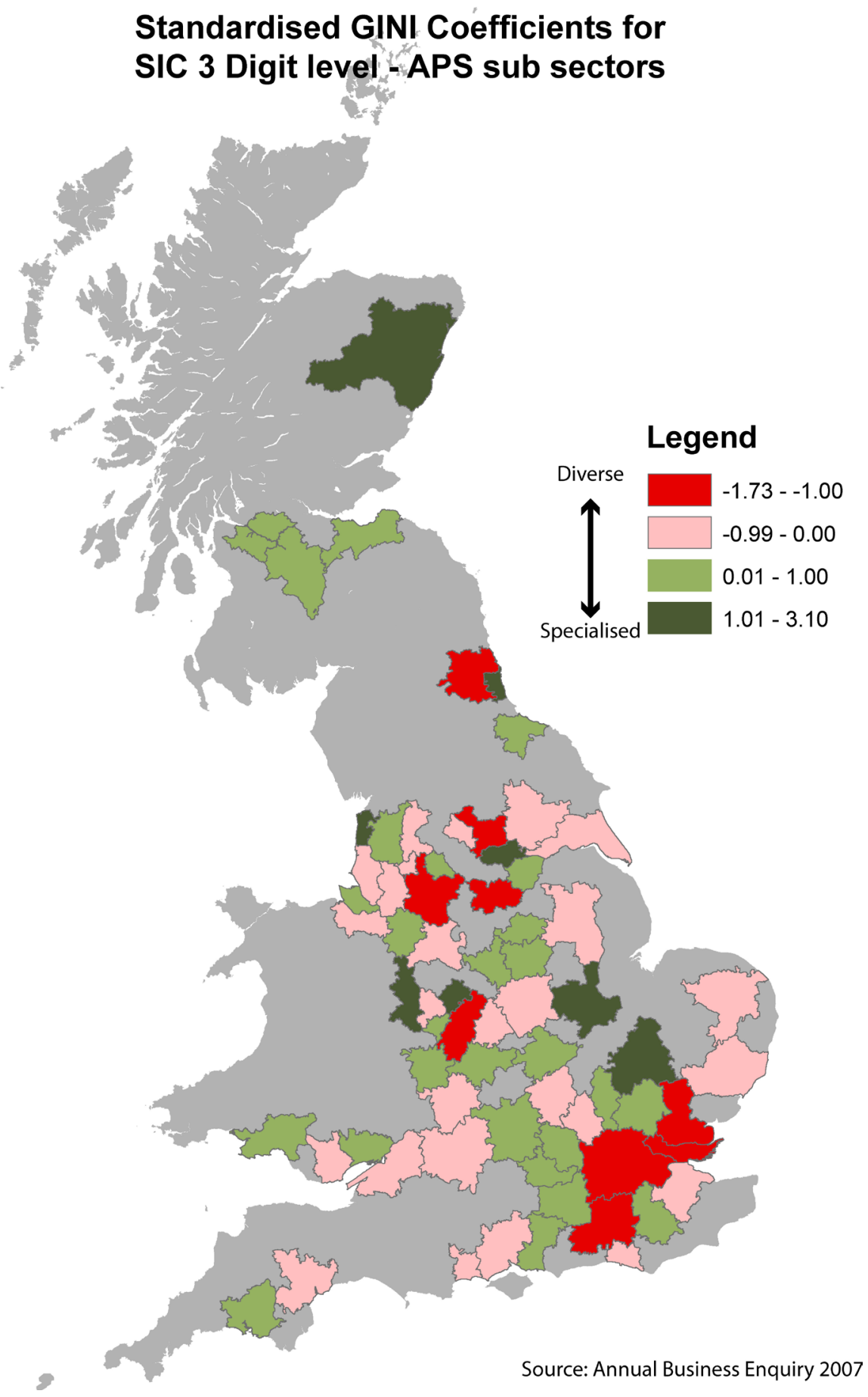

Figure 5. Gini Coefficients for APS sub-sectors.

membership across the three maps, i.e. places that do not change category as one measures the Gini Coefficient with increasing numbers of sectors, it become apparent that most of the largest metropolitan areas emerge as consistently very diverse. These include Manchester, Birmingham, Glasgow, Leeds and Bristol but also Southampton, reinforcing the arguments made above regarding the role of urbanisation in the creation of diverse economies amongst the first tier of British cities. This supports previous research regarding the divergence of 
this group of cities O’Donoghue and Townshend [18] or the distinctiveness of large places more generally Markusen and Shrock [22].

The second key pattern to emerge is when one looks to the opposite end of the spectrum towards places that appear specialised no matter how many sectors are used to measure their employment profiles. Once again Aberdeen emerges across all three maps as a result of its oil-industry cluster Chapman et al. [32], but it is accom-

\section{Standardised GINI Coefficients for SIC 3 Digit level - FIRE sub sectors}

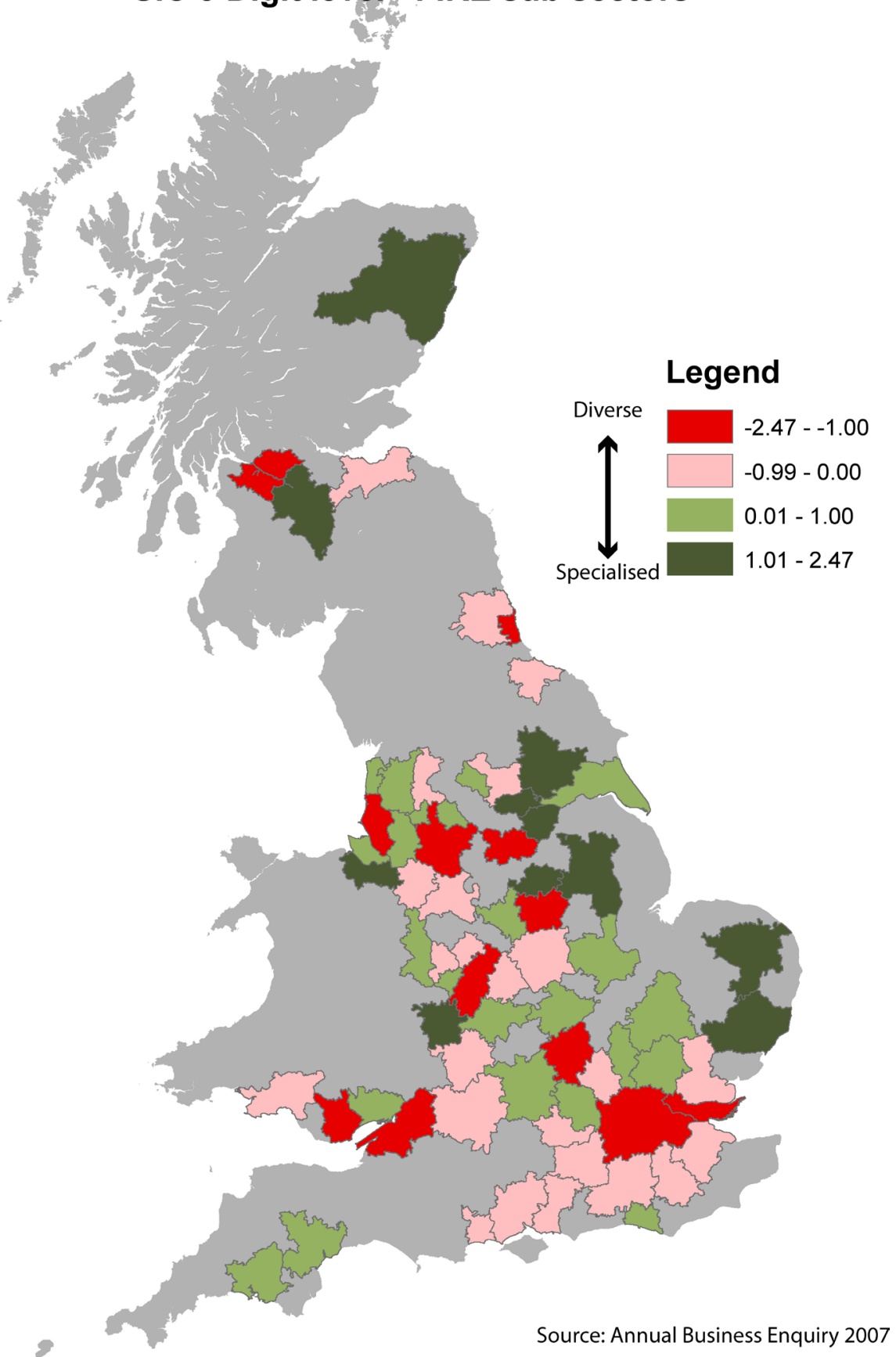

Figure 6. Gini Coefficients for FIRE sub-sectors. 

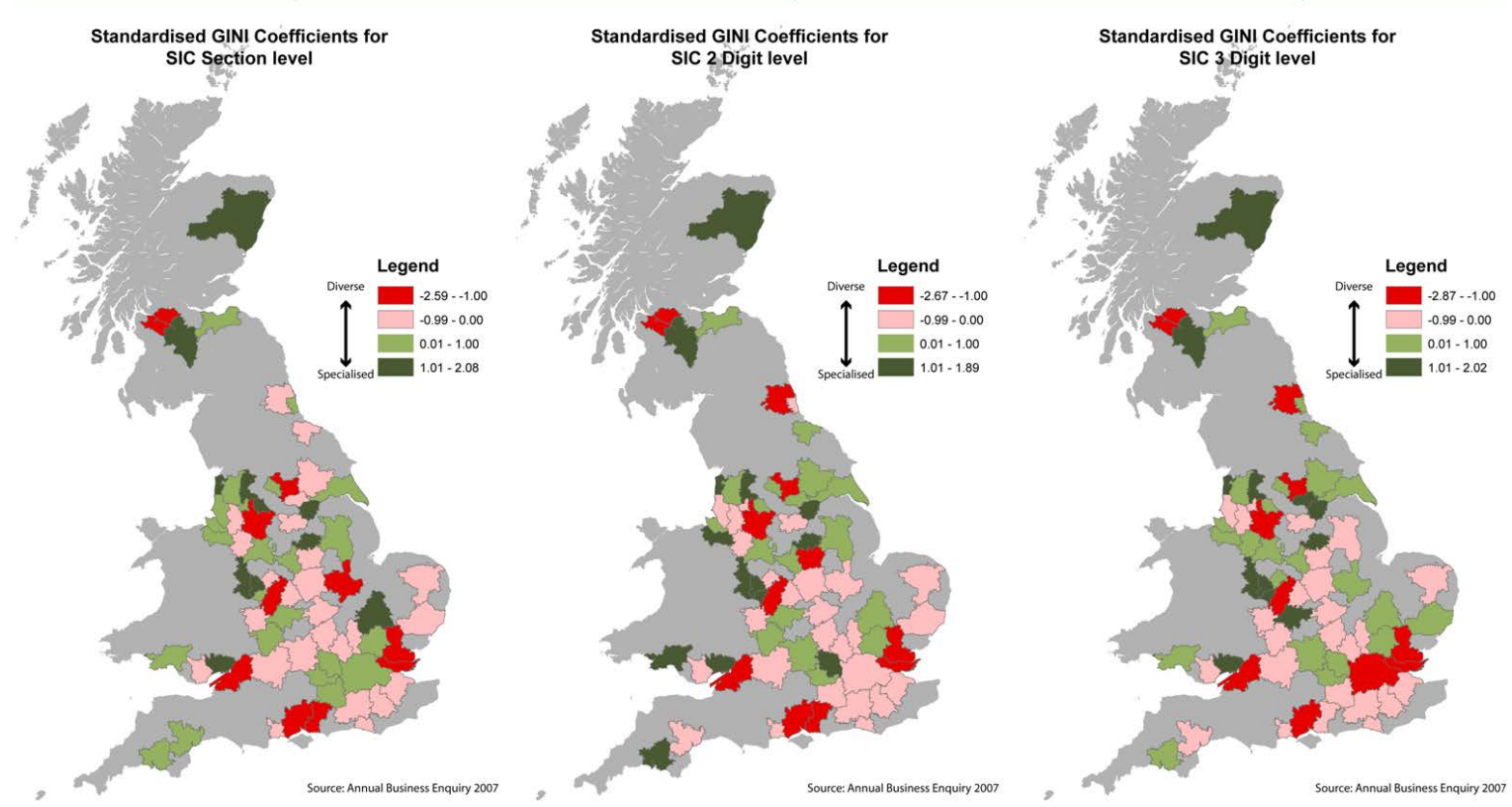

Figure 7. Standardized Gini Coefficients for SIC section, 2-digit and 3-digit levels.

panied by places like Newport, Telford \& Bridgnorth, Mansfield, Blackburn, Blackpool and Doncaster. Whether this can relate to the cluster concept in all cases is uncertain, it may be that many of these places are older industrial cities without the dynamic linkages one would expect to find, however their identification could certainly point us in the right direction if looking for clusters-Aberdeen being a key case in point.

The final and perhaps most important thing to emerge from Figure 7 and something which has not featured strongly thus far is the role of London in the British Urban System. London changes category with each map, or as sectors are added to the calculation of the Gini Coefficient. As one moves from left to right across the maps of Figure 7 London changes from specialised to diverse to very diverse. This is the only city that behaves in this way and is a tribute to London's unique status as a Global City. In a basic analysis London shows up as specialised largely as a result of the financial sector. As one drills down through the SIC, London becomes more diverse relative to other cities as it becomes apparent it has representation and high amounts of employment in just about every sector. Therefore, while outwardly a specialised city focusing on finance, internally London is the most diverse city in the country in terms of representation across all sectors, once again a clear indication of large scale urbanisation economy that London represents. In other words, a totally different type of cluster. In essence, London is made up of "multiple specialisations" and "multiple diversities" that when summed up via a measure of diversity show it to be a truly diverse global city. The case would be even more striking if some alternate measures of diversity were used!

\section{Conclusion}

From the outset it was hoped that this paper would be viewed not as a singular or stand-alone piece of research but as a first step on the road to a greater understanding of diversity and specialisation and the link with the cluster concept. Hopefully this has been achieved using the British urban system as a case study to illustrate how macro level analysis of this kind can be used to explore linkages between varied concepts and to demonstrate how they relate to each other. The results from the paper clearly indicate that there are different ways one may either identify or construct clusters and understand what they represent when considered relative to a range of other cities and configurations of employment. It is clear that there are strong reasons to believe that localisation and urbanisation economies have impacts on cluster formation but perhaps at different scales. It is clear that specialisation and diversity measures can be used to help in the study and conceptualisation of clusters. The roles of "multiple specialisations" or "multiple diversities" and "relatedness" all need further exploration. It is also clear that geographic location, history and path dependency play some role in understanding places and 
their levels of diversity, specialisation and/or clustering. The examples from the British urban system identified a number of clear trends as well as two very distinct and different clusters-London and Aberdeen. Further, more detailed analysis will surely uncover more. There would appear to be plenty of scope for further research that explores these ideas at different scales. It would also seem important to consider looking at the role of occupational diversity in these studies as what has traditionally been called "industrial diversification" is perhaps only telling us one part of the story. In addition, further qualitative work needs to be conducted to explore and explain some of these ideas in far greater depth.

\section{References}

[1] Martin, R. and Sunley, P. (2003) Deconstructing Clusters: Chaotic Concept or Policy Panacea. Journal of Economic Geography, 3, 5-35. http://dx.doi.org/10.1093/jeg/3.1.5

[2] Brenner, T. (2006) Identification of Local Industrial Clusters in Germany. Regional Studies, 40, 1-14. http://dx.doi.org/10.1080/00343400601047408

[3] Vom Hoff, R. and Chen, K. (2006) Whither or Not Industrial Cluster: Conclusions or Confusions? The Industrial Geographer, 4, 2-28.

[4] O’Donoghue, D. and Gleave, W.J. (2004) A Note on Methods for Measuring Industrial Agglomeration. Regional Studies, 38, 419-427. http://dx.doi.org/10.1080/03434002000213932

[5] Kitson, M., Martin, R. and Tyler, P. (2004) Regional Competitiveness: An Elusive yet Key Concept? Regional Studies, 38, 991-999. http://dx.doi.org/10.1080/0034340042000320816

[6] Spencer, G.M., Vinodrai, T., Gertler, M.S. and Wolfe, D.A. (2010) Do Clusters Make a Difference? Defining and Assessing Their Economic Performance. Regional Studies, 44, 697-715. http://dx.doi.org/10.1080/00343400903107736

[7] Coe, N.M. and Townsend, A.R. (1998) Debunking the Myth of Localized Agglomerations: The Development of a Regionalized Service Economy in South-East England. Transactions of the Institute of British Geographers, 23, 385-404. http://dx.doi.org/10.1111/j.0020-2754.1998.00385.x

[8] Bishop, P. and Gripaios, P. (2007) Explaining Spatial Patterns on Industrial Diversity: An Analysis of Sub-Regions in Great Britain. Urban Studies, 44, 1739-1757. http://dx.doi.org/10.1080/00420980701426632

[9] O’Donoghue, D. (1999) The Relationship between Diversification and Growth: Some Evidence from the British Urban System 1978 to 1991. International Journal of Urban and Regional Research, 23, 549-566. http://dx.doi.org/10.1111/1468-2427.00212

[10] Tarzwell, G. (1997) Canadian City Unemployment Rates and the Impact of Economic Diversity. Canadian Journal of Regional Science, XX, 389-399.

[11] Davies, W.K.D. and Donoghue, D. (1993) Economic Diversification and Group Stability in an Urban System: The Case of Canada, 1951-86.Urban Studies, 30, 1165-1186. http://dx.doi.org/10.1080/00420989320081111

[12] Dissart, J.C. (2003) Regional Economic Diversity and Regional Economic Stability: Research Results and Agenda. International Regional Science Review, 26, 423-446. http://dx.doi.org/10.1177/0160017603259083

[13] Shearmur, R. and Polese, M. (2005) Diversity and Employment Growth in Canada, 1971-2001: Can Diversification Policies Succeed? The Canadian Geographer, 49, 272-290. http://dx.doi.org/10.1111/j.0008-3658.2005.00095.x

[14] Seigel, P.B., Johnson, T.G. and Alwang, J. (1995) Regional Economic Diversity and Diversification. Growth and Change, 26, 261-284. http://dx.doi.org/10.1111/j.1468-2257.1995.tb00171.x

[15] Duranton, G. and Puga, D. (2001) Nursery Cities: Urban Diversity, Process Innovation, and the Life Cycle of Products. The American Economic Review, 91, 1454-1477. http://dx.doi.org/10.1257/aer.91.5.1454

[16] Bishop, P. and Gripaios, P. (2010) Spatial Externalities, Relatedness and Sector Employment Growth in Great Britain. Regional Studies, 44, 443-454. http://dx.doi.org/10.1080/00343400802508810

[17] Frenken, K., Van Oort, F. and Verburg, T. (2007) Related Variety, Unrelated Variety and Economic Growth. Regional Studies, 41, 685-697. http://dx.doi.org/10.1080/00343400601120296

[18] O’Donoghue, D. and Townshend, I. (2005) The Diversification, Specialisation, Convergence and Divergence of Sectoral Employment Structures in the British Urban System, 1991-2001. Regional Studies, 39, 585-601. http://dx.doi.org/10.1080/00343400500151830

[19] Markusen, A., Wassall, G.H., DeNatale, D. and Cohen, R. (2008) Defining the Creative Economy: Industry and Occupational Approaches. Economic Development Quarterly, 22, 24-45. http://dx.doi.org/10.1177/0891242407311862

[20] Currid, E. and Stolarick, K. (2010) The Occupation-Industry Mismatch: New Trajectories for Regional Cluster Analysis and Economic Development. Urban Studies, 47, 337-363. http://dx.doi.org/10.1177/0042098009349024

[21] Duranton, G. and Puga, D. (2005) From Sectoral to Functional Urban Specialisation. Journal of Urban Economics, 57, 
343-370. http://dx.doi.org/10.1016/j.jue.2004.12.002

[22] Markusen, A. and Schrock, G. (2006) The Distinctive City: Divergent Patterns in Growth, Hierarchy and Specialisation. Urban Studies, 43, 1301-1323. http://dx.doi.org/10.1080/00420980600776392

[23] Scott, A.J. (2006) Creative Cities: Conceptual Issues and Policy Questions. Journal of Urban Affairs, 28, 1-17. http://dx.doi.org/10.1111/j.0735-2166.2006.00256.x

[24] Florida, R. (2003) Cities and the Creative Class. City \& Community, 2, 13-19. http://dx.doi.org/10.1111/1540-6040.00034

[25] Cutrini, E. (2010) Specialization and Concentration from a Twofold Geographical Perspective: Evidence from Europe. Regional Studies, 44, 315-336. http://dx.doi.org/10.1080/00343400802378743

[26] Malizia, E.E. and Ke, S. (1993) The Influence of Economic Diversity on Employment and Stability. Journal of Regional Science, 33, 221-235. http://dx.doi.org/10.1111/j.1467-9787.1993.tb00222.x

[27] Wagner, J.E. (2000) Regional Economic Diversity: Action, Concept, or State of Confusion. Regional Analysis and Policy, 30, 1-22.

[28] Neffke, F., Henning, M. and Boschma, R. (2011) How Do Regions Diversify over Time? Industry Relatedness and the Development of New Growth Paths in Regions. Economic Geography, 87, 237-265.

[29] Polese, M. and Shearmur, R. (2006) Growth and Location of Economic Activity: The Spatial Dynamics of Industries in Canada 1971-2001. Growth and Change, 37, 362-395. http://dx.doi.org/10.1111/j.1468-2257.2006.00328.x

[30] O’Donoghue, D. (2000) Some Evidence for the Convergence of Employment Structures in the British Urban System from 1978 to 1991. Regional Studies, 34,159-168. http://dx.doi.org/10.1080/00343400050006078

[31] Duncan, S. (1991) The Geography of Gender Divisions of Labour in Britain. Transactions of the Institute of British Geographers, 16, 420-439.

[32] Chapman, K., MacKinnon, D. and Cumbers, A. (2004) Adjustment or Renewal in Regional Clusters? A Study of Diversification amongst SMEs in the Aberdeen Oil Complex. Transactions of the British Institute of Geographers, 29, 382-396. http://dx.doi.org/10.1111/j.0020-2754.2004.00250.x

\section{Submit or recommend next manuscript to SCIRP and we will provide best service for you:}

Accepting pre-submission inquiries through Email, Facebook, Linkedin, Twitter, etc A wide selection of journals (inclusive of 9 subjects, more than 200 journals)

Providing a 24-hour high-quality service

User-friendly online submission system

Fair and swift peer-review system

Efficient typesetting and proofreading procedure

Display of the result of downloads and visits, as well as the number of cited articles

Maximum dissemination of your research work

Submit your manuscript at: http://papersubmission.scirp.org/ 